\title{
Targeting Cellular Receptors as a Strategy for the Development of New Generation Mucosal Vaccines
}

\author{
${ }^{1}$ Constantine Bitsaktsis, ${ }^{1}$ Kari Wiedinger and ${ }^{2}$ Edmund Joseph Gosselin \\ ${ }^{1}$ Department of Biological Sciences, \\ Seton Hall University, 400 South Orange Ave., South Orange, 07079, New Jersey \\ ${ }^{2}$ Center for Immunology and Microbial Disease, MC-151, \\ Albany Medical College, 47 New Scotland Avenue, Albany, 12208, New York
}

Received 2012-12-05, Revised 2013-01-04; Accepted 2013-04-02

\begin{abstract}
Mucosal pathogens are a primary source of infection that require the development of vaccines to induce a specific, protective and long lasting immune response. Despite an urgent need, development of effective mucosal immunization strategies has proven difficult. The literature was reviewed to elucidate cell specific targets that may be utilized to increase the immunogenicity of protective antigens through mucosal vaccination. Vaccine vehicles such as liposomes, outer membrane vesicles and Poly Lactic Acid (PLA) nanoparticles serve as antigen delivery systems as well as immuno-stimulatory agents. Even with the advances in mucosal vaccine delivery mechanisms many systems lack specificity and fail to generate a protective immune response. Hence, targeting extracellular receptors by harnessing antibody specificities, bacterial molecules, or toxins in conjunction with protective antigens provides an attractive alternative to conventional vaccine regiments that may circumvent the need for delivery systems and adjuvants. Fusion proteins targeting $M$ cells, dendritic cells, or lymphocytes, are promising candidates for enhancing antigenic trafficking across the mucosal membrane and subsequent uptake by antigen presenting cells. Directing antigens to extracellular receptors of epithelial and immune cells via mucosal immunization provides an attractive model for generating a protective memory immune response that is essential to a successful vaccine regiment.
\end{abstract}

Keywords: Mucosal Vaccines, Targeting, Cell Receptors, Poly Lactic Acid (PLA)

\section{INTRODUCTION}

The vast majority of infectious diseases are caused by pathogens that invade the body via the mucosal surfaces. Thus, there is an urgent need for vaccines that will induce protective and long-lasting immunity against mucosal pathogens, especially in infants and children. However, despite its attractive, needle-free administration, effective mucosal immunization has proven difficult. Mucosal vaccines have been known to get diluted in mucosal fluids or get stuck within the mucus gel and subsequently get degraded by proteases (Neutra and Kozlowski, 2006). In addition, deciphering the dose and route of vaccination, the timing of boosters and the choice of adjuvant may make the all-important difference between establishing a protective, memory immune response and unwillingly achieving mucosal tolerance.

Mucosal surfaces are protected from pathogenic organisms by physicochemical and cellular barriers that comprise the innate immune system, as well as by the highly specific and inducible adaptive responses. Epithelial cells line most mucosal surfaces creating a complex cellular mesh that blocks pathogen invasion. In addition, antibodies produced by B lymphocytes, have

Corresponding Author: Constantine Bitsaktsis, Department of Biological Sciences, Seton Hall University, 400 South Orange Ave., South Orange, 07079, New Jersey 
neutralizing properties against bacterial and viral molecules, blocking pathogen attachment on mucosal surfaces and facilitating aggregation and opsonophagocytosis of the microbes. These effector functions are mediated primarily by $\operatorname{IgA}$ which dominates in the mucosal surfaces in its secretory form (sIgA) (Lamm, 1997).

Although the ability to elicit a strong antibody response is key for a successful vaccine, cellular immunity at mucosal surfaces has also been proven critical in both regulating immune responses and driving direct effector functions. For example, in the case of a live attenuated influenza vaccine, cytotoxic $\mathrm{CD} 8+\mathrm{T}$ cell responses are thought to contribute significantly to cross-reactive protection against various influenza strains (Sun et al., 2011), while TH17 cells have been shown to block bacterial colonization during Salmonella infection in the intestines of immunized mice (Godinez et al., 2008).

The initial step of vaccine development entails the identification of a protective antigen, the choice of an adjuvant and the decision upon the route of administration. Ideally, a successful mucosal vaccine should: (1) preserve vaccine antigens from enzymatic degradation, (2) limit their elimination or dilution in the organisms, (3) facilitate its transport through the mucosal epithelial linings and (4) ensure an efficient uptake by professional Antigen Presenting Cells (pAPCs), such as Dendritic Cells (DCs) and macrophages. Professional APCs will process and present the vaccine antigens to $T$ cells via in an MHC dependent fashion, thus, driving the initiation of a protective and long-lasting adaptive immune response.

The paucity of mucosal adjuvants and delivery systems has led scientists to study vaccine approaches that target protective antigens to specific cellular receptors. Doing so, we can increase the immunogenicity of an antigen and bias the immune system to develop adaptive immune responses specific to that particular antigen, hence, eliciting long-lasting protection against subsequent challenge with the infectious agent.

Targeting to cellular receptors is usually achieved by exploiting antibody specificities. Antigens have been physically, chemically, or genetically linked to antibody molecules, or Fab' fragments, that target specific cellular receptors. If these receptors are expressed on epithelial cells, such as the specialized $M$ cells, then the vaccine has the advantage of easily crossing the epithelial barrier. If, on the other hand, the vaccine targets activating receptors on pAPCs, such as DCs, then enhanced antigen uptake and presentation will be accompanied by maturation and activation of the pAPCs that will in turn drive the generation of effective lymphocyte responses.

In this review we will focus on the various vaccine strategies that target antigens to different extracellular receptors in order to facilitate their trafficking through the epithelial cell lining and their subsequent uptake by pAPC for processing and presentation. Such approaches have yielded promising results in a wide range of infectious models that use both bacterial and viral mucosal pathogens.

\subsection{Mucosal Adjuvants and Vaccine Delivery Modes}

Vaccines comprised of attenuated microorganisms, although relatively immunogenic, run the risk of causing disease. This caveat has led research to identify microbial fractions, or even isolated specific proteins, as vaccine candidates to replace the use of whole microorganisms. The shortcoming of this approach is that these subunit vaccines are usually poorly immunogenic, hence requiring the use of adjuvants that will boost or enhance specific immune responses, ultimately establishing protective immunity (Kensil et al., 2004; McCluskie et al., 1998; Vogel, 2000). Although innate immune responses usually suffice to protect against mucosal pathogens, the ability of the latter to evade effector responses, including phagocytosis and complement mediated lysis, renders the adaptive branch of the immune system critical to resolving mucosal infections (Blank et al., 2011; Cooper et al., 2002; Klinman et al., 1999). Thus, it is important that adjuvants will enhance specific $\mathrm{T}$ and $\mathrm{B}$ lymphocyte responses while establishing immunologic memory.

Vaccine adjuvants can be divided into two broad categories: Immune modulators and delivery systems (Kensil et al., 2004). Currently, the only FDA approved adjuvant in the United States is the hydrated potassium aluminium sulfate (Alum) which is impractical for the delivery of mucosal vaccines and also fails to generate robust cellular immune responses as it initiates a TH2 biased immunologic profile (Brewer et al., 1999). Consequently, there is an unmet need for safe and effective mucosal immunization vaccine strategies and for the identification of alternative, yet safe mucosal vaccine adjuvants.

Current research has utilized various vaccine vehicles that not only deliver vaccines to and through mucosal surfaces but also have immunostimulatory abilities. 


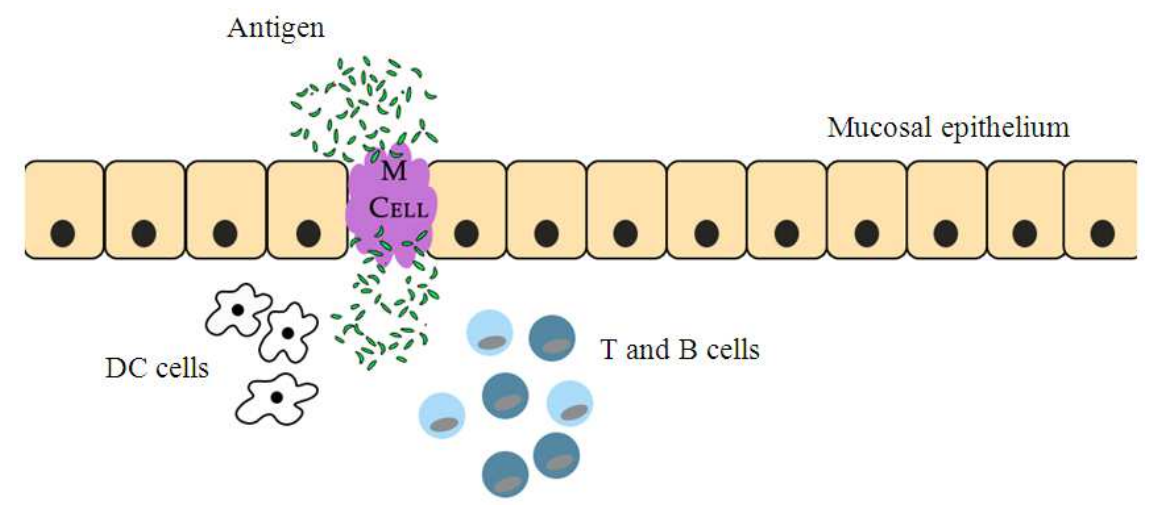

Fig. 1. $M$ cells are important carriers of antigens through the epithelial layers to the mucosa-associated lymphoid tissues, making them available for uptake by pAPCs, such as DCs, processing and presentation to T and B lymphocytes

For example, liposomes, Immune Stimulating Complexes (ISCOMs), monoglycerides with fatty acids and Outer Membrane Vesicles (OMV) have been evaluated giving promising results (Hu et al., 2001; Mann et al., 2009; Mitragotri, 2005). In addition, antigens encapsulated in PLA or PLGA nanoparticles have generated strong mucosal and systemic immune responses, both in mice (Song et al., 2008) and humans (Katz et al., 2003). Nanocarriers, having comparable dimensions to bacterial pathogens, are efficiently taken up by phagocytosis, thus delivering the antigens to pAPCs. Alternatively, recombinant or attenuated strains of various bacteria, such as Salmonella, E. coli, or Listeria, have been also used as vectors to deliver antigens to the Mucosal Associated Lymphoid Tissue (MALT) (Hall et al., 2009; Boyer et al., 2005). These vectors not only target the DNA or peptide vaccine construct to pAPCs, but also provide a strong danger signal, acting as natural adjuvants, thereby promoting maturation and activation of DCs (Mayr et al., 2005).

However, despite the significant advances in the area of vaccine delivery, most approaches lack in specificity, thus creating potential hypersensitivity issues, or they are simply unable to specifically moderate the immune system towards a desired, protective immune response. Targeting antigens to receptors expressed on epithelial cells and pAPCs, not only circumvents the need for an adjuvant or a delivery system, but also provides us with the ability to specifically manipulate the immune system to our advantage, eliciting the best possible protection against mucosal pathogens.

\subsection{Cells-The Gateway to Mucosal-Associated Lymphoid Tissues}

$\mathrm{M}$ cells are specialized epithelial cells responsible for sampling antigens at the interface of mucosal surfaces and the environment and presenting them to the mucosal immune system (Fig. 1). Once antigens are trancytosed by $M$ cells they can quickly move to the basolateral membrane and interact with the underlying lymphoid aggregates (Owen, 1977). Thus, the high transcytotic ability of $M$ cells and their strategic location at the mucosal interface, make them an attractive target for mucosally delivered vaccines. Below we describe a number of delivery systems, bacterial molecules, toxins and antibodies that have been used to target $\mathrm{M}$ cells.

\subsection{Lectin-Mediated Targeting}

Lectins, often expressed on M cells, are a structurally diverse group of proteins and glycoproteins that bind on carbohydrate moieties of cell-surface proteins and lipids. Targeting lectins on $\mathrm{M}$ cells has been shown to increase antigen uptake and transport through the epithelium (Clark et al., 2000; Jepson et al., 2004; Azizi et al., 2010; Chen et al., 1996). Indeed, these studies have shown that nanoparticles coated with the lectin-ligands such as Wheat Germagglutinin (WGA) and Concanavalin A (ConA) enhanced the endocytosis of nanoparticles by murine intestinal epithelial cells. One of the most investigated lectin is Ulex Europeans Agglutinin 1 (UEA-1), which binds to a-L-fucose residues expressed on the apical surface of $M$ cells in mice (Gupta et al., 2007). Upon oral immunization of mice with UEA-1, chemically anchored to the surface of Hepatitis B surface Antigen (HBsA)-loaded nanoparticles, increased HBsA-specific sIgA responses and mediated a strong TH1-like immune response (Gupta et al., 2007). In a different study, mice immunized via the oro-gastric route with either UEA-1agglutinated $H$. pylori or UEA-1-agglutinated $C$. jejuni showed significantly enhanced bacteria-specific IgG and 
IgA antibody responses in their vaginal washings, compared to mice receiving non-agglutinated bacteria (Chionh and Sutton, 2010). However, because UEA-1 also reacts strongly with goblet cells and the mucous layer covering the intestinal epithelium due to the existence of abundant sialic acids (Kandori et al., 1996), scientists have developed monoclonal antibodies that specifically target lectins expressed solely on $\mathrm{M}$ cells. For example, Nochi and colleagues developed an oral vaccine comprising of the Botulism Toxoid (BT)conjugated to the antibody NKM 16-2-4, which shows specificity for $\alpha(1,2)$-fucosylated $M$ cells. Oral immunization of Chinese hamsters with this vaccine construct resulted in robust anti-BT specific antibody responses which were significantly higher compared to the use of UEA-1 or the BT toxoid alone.

However utilization of lectins as targeting molecules for mucosal immunization presents challenges for oral vaccine delivery due to their potential toxicity and possible degradation of the lectin once anchored onto nanoparticles (Russell-Jones, 2001). Vaccine delivery could be further limited as intestinal glycosylation patterns of $\mathrm{M}$ cells vary at differing locations within the intestine (Lavelle and O'Hagen, 2006). In addition, some lectins have been found to be highly immunogenic which may inhibit uptake of the constructs by mucosal epithelial cells due to the generation of local innate immune responses against the lectin-targeting molecule (Clark et al., 2000). However, the immunostimulatory capacity of lectins may present an alternate role for lectin ligands as mucosal adjuvants.

\subsection{Targeting Pattern Recognition Receptors (PRRs)}

PRRs on various cell types, including pAPCs and epithelial cells, can recognize Pathogen Associated Molecular Patterns (PAMPs), such as LPS, enhancing attachment and phagocytosis of microorganisms (Chadwick et al., 2009). For instance, TLR-4, the natural ligand of LPS, has been shown to be expressed on M cells and be involved in bacterial translocation (Neal et al., 2006; Tyrer et al., 2006). Unsurprisingly, nanoparticles coated with LPS were uptaken more effectively by mouse $M$ cells in the intestinal epithelial compared to their control counterparts, indicating a novel targeting and transport pathway through the mucosal layers (Gribar et al., 2008).

\subsection{Use of Bacterial Toxins for M Cell Targeting}

Cholera Toxin (CT) from Vibrio cholera and the heat-Labile Enterotoxin (LT) from Enterotoxigenic E. Coli (ETEC) are structurally related $\mathrm{AB}_{5}$ enterotoxins, composed of an enzymatically active A subunit, which mediates their toxicity and a pentameric B subunit that binds with high affinity to ganglioside receptors expressed on the apical surface of $\mathrm{M}$ cells (Cheesman et al., 2004). Intranasal or oral immunization of mice with attenuated pathogens, or protective antigens, chemically or genetically conjugated to these toxins, or their respective B subunits, generated protection against subsequent lethal challenge with these pathogens (Jang et al., 2004; Bergquist et al., 1998; Rask et al., 2000). Moreover, coupling of Cholera Toxin B subunit (CTB) to antigenloaded liposomes generated enhanced mucosal immune responses in mice as compared to untargeted antigen loaded particles (Harokopakis et al., 1998). Similarly, Clostridium Perfringens Enterotoxin (CPE), specifically binds with high affinity to Claudin-4, a protein associated with $M$ cell endocytosis, thus presenting an alternative toxin utilized for $\mathrm{M}$ cell targeting.

\subsection{Utilization of other Receptors as Targeting Candidates for Vaccine Transport Across the Mucosal Epithelia}

Different studies have shown the expression of other receptors on $\mathrm{M}$ cells that could provide additional candidates for targeting vaccine approaches. For example, when latex nanoparticles coated with purified invasin (binds to b1 integrins) from Yersinia pestis were administered orally to rats, six times more invasin-coated nanoparticles were found in the circulation than uncoated ones (Hussain and Florence, 1998), confirming the expression of integrin receptors on epithelial cells. Similarly, the coating of nanoparticles with fibronectin, an endogenous ligand for a $5 \mathrm{~b} 1$ integrin, significantly increased the binding of nanoparticles to the Peyers patches and their active transport across the intestinal epithelium (Gullberg et al., 2006).

In addition, some complement receptors have been identified on epithelial cells and utilized for antigen targeting. For instance, Kim et al. (2011) showed the expression of $\mathrm{C} 5$ a complement receptor on the surface of $\mathrm{M}$ cells. In this novel approach, oral administration of Yersinia enterolytica expressing Outer membrane Protein $\mathrm{H}(\mathrm{OmpH})$, a ligand of $\mathrm{C} 5 \mathrm{aR}$, led to enhanced antigen-specific local and systemic immune responses to the pathogen.

Finally, adult epithelial cells in both mice and humans express the neonatal Fc Receptor (FcRn) which binds with variable affinities to the Fc portion of the different IgG antibody sub-classes, thus mediating the trans-epithelial transport of IgG (Roopenian and Akilesh, 2007; Yoshida et al., 2004; Ward and Ober, 2009). 
Hence, mucosal vaccination with Immune Complexes (IC) formed between $\operatorname{IgG}$ antibodies and whole, attenuated microorganisms, or merely protective antigens, can enhance the transport of the vaccine through the epithelial layers, therefore increasing its accessibility to the lymphoid tissues. Indeed, in a study carried out by Chopra (1998), intranasal immunization with inactivated Francisella tularensis (iFt) coupled with an anti-LPS IgG2a mAb, increased protection against subsequent lethal challenge with the live bacterium, compared to immunization with iFt alone. This protection was abrogated when FcRngenetically deficient mice were used. In a similar study, mucosal immunization with the HIV protein, gag, genetically fused to the heavy chain of IgG (GagFc), increased the transport of the protein through the epithelial layers, thus increasing its immunogenicity (Singh et al., 2001).

\subsection{Targeting Dendritic Cells (DCs)-Building a Link between Innate and Adaptive Immunity}

Presentation of antigen to T lymphocytes by DCs is highly efficient due to the constitutive, high expression of MHC class II and other costimulatory molecules on the surface of these pAPCs. Thus, targeting DCs as a vaccine strategy has been the focus of many research groups. Apart from the obvious advantages of antigen uptake and presentation to $\mathrm{T}$ cells, DCs have been recently shown to be involved in the transport of antigens through mucosal surfaces, mainly in the absence of differentiated $\mathrm{M}$ cells, via their dendrites that protrude across the intestinal epithelial layer and into the lumen (Rescigno and Sabatino, 2009). The "ferried" antigens can then be presented to conventional CD4+and CD8+T cells of the MALT, thus ensuring a specific, adaptive immune response. Subsequent activation of lymphocytes will drive robust effector functions and also lead to the expression of tissue-homing receptors that will allow lymphocytes to traffic to areas of antigenic exposure (Iwasaki, 2007; Johansson-Lindbom et al., 2005; Mora et al., 2006; Devriendt et al., 2001). The importance of DCs in mucosal immune responses was further demonstrated by a study from Fahlen-Yrlid et al. (2009) in which administration of OVA intranasally led to the production of sIgA-specific antibodies only in the presence of Conventional DCs (CD11 $\left.\mathrm{c}^{\text {high }}\right)$.

It is noteworthy that DCs of the Respiratory Track (RTDCs) have been shown to play different roles in controlling the immunological homeostasis of inhaled antigens (Stumbles et al., 2003). Recent findings have suggested that the DC subsets of the airway mucosa do not have identical abilities to sample and present antigen, thus, understanding the role played by each DC subpopulation will be key for the development of mucosal vaccines (Garnier and Nicod, 2009; Garnier et al., 2007; Wikstrom and Stumbles, 2007).

Hence, it is evident that targeting antigens to DCs in the mucosa is a way to understand and exploit the specific functions of the various DC subtypes residing or recruited to these tissues, leading to the generation of better vaccines. Unfortunately, there are very few, if any, DC-specific markers. Nevertheless, the majority of receptors expressed on the surface of DCs are involved in endocytosis and antigen presentation, therefore presenting attractive candidates for vaccine targeting.

\subsection{C-Type Lectin (CLR) Targeting}

CLRs are pattern recognition receptors that are widely expressed on various APC populations (Gordon, 2002; Pyz et al., 2006). Through their carbohydraterecognition domains, CLRs selectively bind to glycans associated with microorganisms and lead to rapid internalization (Brown et al., 2003; Mansour et al., 2006). CLRs include the Mannose Receptors (MR), DEC-205 and DC-SIGN (DC-specific ICAM-grabbing non-integrin). MR expression is abundant on mouse bone-marrow derived DCs, human monocyte-derived DCs and interstitial DCs, such as Langerhans cells (Sallusto et al., 1995; Uccini et al., 1997). Ligands containing mannan or mannose have been successfully used in various forms to direct antigens to APCs, thus generating more efficient immune responses (Agnes et al., 1998; Keler et al., 2004).

Another CLR, DEC-205, is highly expressed on human and murine DCs, especially in the T-cell rich areas of the secondary lymphoid organs (Jiang et al., 1995). Initial studies demonstrated the ability of rabbit antibodies, specific for DEC-205, to be presented to reactive $\mathrm{T}$-cell hybridomas 100 -fold more efficiently than irrelevant antibodies (Jiang et al., 1995). Despite its "in vitro" promise, generation of protective immune responses in infectious models following targeting to DEC-205 requires co-administration of an adjuvant, such as anti-CD40, heat-shock protein 70 (HSP-70), poly-IC, or a TLR agonist (Stylianou et al., 2011; Bonifaz et al., 2002; Lazarevic et al., 2003; Wang et al., 2001; 2009; Uehori et al., 2005). It is important to note that in the absence of adjuvants, targeting antigens to DEC-205 alone may result in mucosal tolerance; a detrimental outcome in vaccine research.

Another receptor utilized in antibody-mediated Clectin targeting on DCs is DC-SIGN. Antigens targeted to this CLR are uptaken rapidly by multiple DC populations contributing to T-cell priming and activation (Schjetne et al., 2002; Dakappagari et al., 2006). Indeed, 
the rapidly internalized antigen and its subsequent routing to the lysosomal compartments would lead to effective processing and presentation to T cells. Nevertheless, there is a paucity of studies assessing this targeting approach in infectious models "in vivo".

\subsection{Targeting Toll-like Receptors (TLRs)}

TLRs are an essential family of pattern-recognition receptors, abundantly expressed in murine and human DCs, either intracellularly or extracellularly. A number of studies have highlighted the importance of TLRs and the critical role they play in integrating innate and adaptive immunity (Reise-Sousa, 2004; Mazzoni and Segal, 2004). These novel insights have provided impetus for developing new vaccines against various mucosal pathogens that target TLRs. For example, when the Cytomegalovirus (CMV) vaccine, gB, was administered in mice with $\mathrm{CpG}$, the natural ligand for TLR-9, it resulted in the generation of long-lived Agspecific $\mathrm{T}$ cells and antibodies with cross-neutralizing activity against heterologous CMV strains (Dasari et al., 2011). In a similar study, murine administration of HIV gag and nef proteins with $\mathrm{CpG}$ increased the maturation levels of DCs, as depicted by the expression levels of costimulatory molecules, while it resulted in the generation of $\mathrm{HIV}$-specific $\mathrm{CD} 8+\mathrm{T}$ cells, providing evidence for cross-presentation (Lore et al., 2003). However, the relatively scarce expression of TLR-9 on human DCs (Jarrossay et al., 2001; Krug et al., 2001) led Wille-Reece and colleagues to co-administer the TLR$7 / 8$ agonist, R848, together with the HIV proteins and $\mathrm{CpG}$. Indeed, the generation of HIV-specific CD8+ T cells and the production of TH1-like cytokines in the sera of immunized mice were improved significantly compared to the previous study in which TLR-9 was the targeted receptor. The potential superiority of TLR-7 over TLR-9 was further demonstrated in a murine influenza model study by Schmitz et al. (2012), in which mice were immunized with the viral extracellular domain, M2, targeted to TLR-7. The resulting anti-influenza $\operatorname{IgG} 2 \mathrm{c}$ high titer was indicative of a protective, TH-1 like response.

Another example of TLR targeting via its natural ligand is TLR-5. Bacterial flagellin binds to a leucinerich repeat of TLR-5 and induces downstream signaling in a MyD88-dependent manner (Mizel et al., 2003; Hayashi et al., 2001). The adjuvant effect of flagellin leads to increased cytokine production (Applequist et al., 2005; Bachmann et al., 2006; Didierlaurent et al., 2004; Cuadros et al., 2004), increased lymphocyte trafficking in the draining lymph nodes (Bates et al., 2008) and activation of CD11c $\mathrm{c}^{\text {high }}$ DCs (Bates et al., 2009). Consequently, vaccination of mice with fusion proteins comprising of flagellin and bacterial or viral antigens results in high antibody titres and occasionally protection against a wide range of mucosal pathogens, including but not limited to: Yersinia pestis (Mizel et al., 2009), West Nile virus (McDonald et al., 2007), Pseudomonas aeruginosa (Weimer et al., 2009), Vaccinia virus (Delaney et al., 2010) and Streptococcus pneumoniae (Nguyen et al., 2011).

Furthermore, vaccines containing TLR-2 agonists, or its natural ligands, such as Neisseria meningitides PorB, protected mice against herpes simplex type 2 challenge and experimental tularemia (Zhang et al., 2009; Chiavolini et al., 2008). The high-expression of TLR-2 on genital track DCs would make this targeted receptor an attractive candidate, especially for intravaginal immunization regimes.

Finally, TLR-4, although widely expressed on various DC sub-populations, has been met with skepticism as a vaccine targeted molecule. Its natural ligand, Lipopolysaccharide (LPS), causes activation of innate cells and secretion of pro-inflammatory cytokines, although it initially plays a significant protective role against intracellular pathogens, prolonged exposure may lead to microbial sepsis and tissue necrosis. Hence, the effect of a vaccine strategy targeting TLR-4 should be tightly regulated in order to avoid any unfavorable toxic side-effects.

\subsection{Targeting Fc Receptors (FcR)}

FcR are immunoglobulin receptors, widely expressed throughout the immune system. By binding to the Fc portion of antibodies, FcR provide a link between the powerful effector functions of the innate immune cells and the specificity of the adaptive immune system. Numerous studies have demonstrated that targeting antigens to FcR and in particular the activating Fc $\gamma R I$,

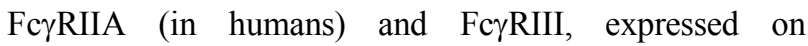
monocytes, macrophages, DCs, basophils and mast cells, enhanced humoral and cellular immune responses both "in vitro" and "in vivo" (Fig. 2) (Adamova et al., 2005; Gosselin et al., 1992; Guyre et al., 1997; Keler et al., 2000; Liu et al., 1996; Rawool et al., 2008; Snider et al., 1990; Walsh et al., 2003). Cross-linking Fc $\gamma \mathrm{R}$ transduces signals to the interior of the cell, which can be stimulatory or inhibitory in nature depending on what signaling molecules are associated with the cytoplasmic tails of the FcR in question. 


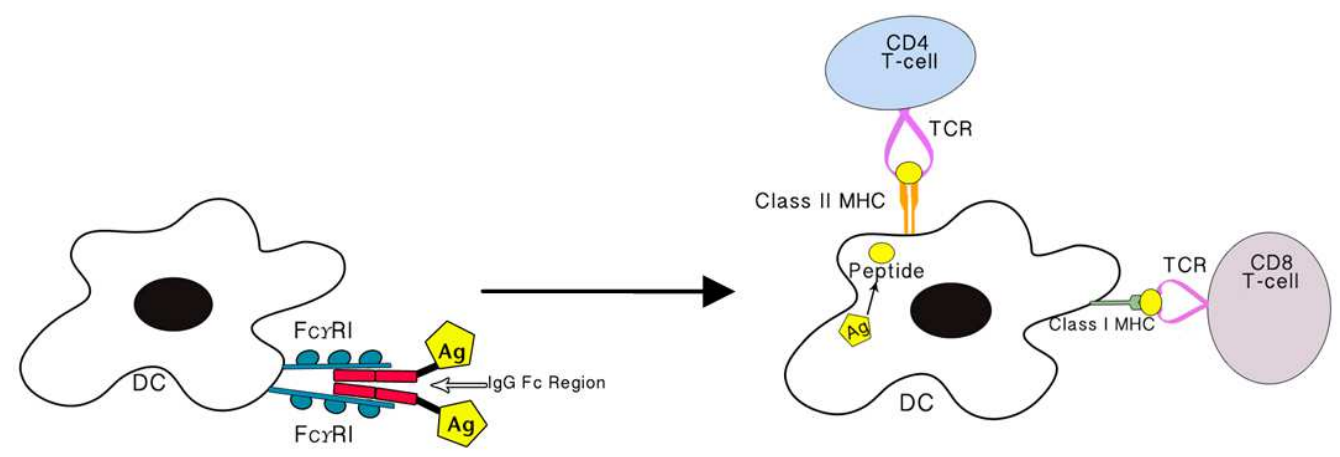

Fig. 2. Cross-linking the activating FcyRI receptors expressed on pAPCs, such as DCs, will enhance the uptake, processing and presentation of antigens to T lymphocytes

For example, the activating Fc $\gamma$ RI generates stimulatory signals via the immunoreceptor Tyrosine-Based Activation Motif (ITAM), while inhibitory signals are generated via the immunoreceptor tyrosine-based Inhibition Motif (ITIM), following cross-linking of Fc $\gamma$ RIIB, both in humans and mice (Daeron, 1997; Gessner et al., 1998). Thus, FcRs have a dual function on DCs: First, they will bind Immune Complexes (IC) facilitating uptake, processing and presentation of the antigen via MHC molecules, leading to $\mathrm{T}$ lymphocyte priming. Second, ICs will generate activating or inhibitory signals depending upon which FcRs they will cross-link on the DCs (Dhodapkar et al., 2002; Gosselin et al., 2009; Kalergis and Ravetch, 2002; Rafiq et al., 2002), hence affecting the outcome of the immune response. Consequently, FcRs are involved in regulating a multitude of innate and adaptive immune responses, which makes them attractive targets for vaccine strategies. Indeed, immunization with hepatitis B antigen$\mathrm{Ab}$ complex enhanced antigen-specific IgG1 production, while in a different study, intranasal immunization of mice with Streptococcus mutants-Ab complex influenced the immunoglobulin isotype and humoral immune response against the pathogen (McCliskie and Davison, 1990; Brady et al., 2000; Rhodin et al., 2004). In our own studies, in, immunization of mice with fixed $F$. tularensis, LVS and anti-LPS IgG2a mAb ICs generated a protective, TH1-like response, against subsequent lethal LVS challenge (Rawool et al., 2008).

A significant disadvantage of utilizing an IC or Fc$\mathrm{Ag}$ fusion protein techniques is the lack of specificity, allowing for targeting of the inhibitory Fc $\gamma$ RIIB receptor, potentially suppressing the immune response. This problem can potentially be circumvented by using recombinant DNA technology: In one of our recent studies, we targeted the $S$. pneumoniae protective antigen, PspA, to human Fc $\gamma \mathrm{RI}$ in a transgenic mouse model, generating a pathogen-specific cellular and humoral immune response that protected mice against infection with S. pneumoniae serotype 3 (Bitsaktsis et al., 2012). By utilizing this specific targeting approach we avoided binding and activation of the inhibitory Fc $\gamma$ RIIB, thus generated enhanced protective immune responses.

It is also important to note that the majority of $\operatorname{IgG}$ $\mathrm{Ab}$ subclasses bind the neonatal receptor, FcRn, expressed on epithelial cells. Hence, targeting to Fc $\gamma$ Rs is effective not only for its direct activating capabilities on pAPCs, such as DCs, but also because it facilitates trafficking through the epithelial layers and into the lymphocyte-rich mucosa-associated lymphoid tissues, leading to the generation of effective adaptive immune responses. Thus, construction of a fusion protein that specifically targets both the activating Fc $\gamma$ RI, as well as the epithelial transport pathways (via the $\mathrm{M}$ cells) would provide a superior approach in the generation of FcRtargeted mucosal vaccines.

\subsection{Targeting Ganglioside Receptors}

Apart from on $\mathrm{M}$ cells, ganglioside receptors are also expressed on many subpopulations of DCs and are shown to be involved in antigen uptake (Grdic et al., 2005; Kawamura et al., 2003). In addition, ligation of ganglioside receptors on DCs causes the activation and maturation of the latter via an NF-kappaB-mediated pathway (Kawamura et al., 2003). Thus, targeting antigens to ganglioside receptors, mainly by fusing them genetically or chemically to $\mathrm{AB}_{5}$ enterotoxins, enhances immune responses specific to the antigen. Due to the potential side effects of these toxins, various toxin subunits have been utilized that circumvent the problem 
of toxicity while maintaining the adjuvanicity of the toxin. More specifically, intravaginal immunization of mice with a fusion protein comprising of the Chlamydia protective antigen, MOMP and the non-toxic subunit of cholera toxin, CTA2B, induced DC maturation and proliferation, while it established long-term, protective anti-chlamydial immunity (Ekong et al., 2009). Similarly, intranasal co-administration of fixed $F$. tularensis bacteria with CTB, a different non-toxic subunit of CT, has also proven effective against lethal infection with $F$. tularensis, LVS, via the generation of a strong TH1-like response (Bitsaktsis et al., 2009). In the latter study, CTB was not linked to the antigen, thus it is likely that the immunostimulatory effect was via binding of CTB to other receptors as well, such as TLRs, causing a more generalized activation of the innate immune system. Although these approaches have proved promising, the potential use of such toxins in the clinical setting raises regulatory concerns. Intranasal administration of CT and CTB has been shown to promote uptake of vaccine proteins in epithelial olfactory nerves and subsequent transportation into olfactory bulbs, increasing the possibility of neuronal damage. A way to circumvent the problem of toxin accumulation in the olfactory nerves, cholera toxin has been incubated with its ligand, GM1, prior to intranasal administration in order to minimize binding to the neuronal cells.

\subsection{Targeting other Novel DC Ligands}

In order to establish new vaccine platforms that target DCs, a phage-display peptide library has been used to identify various $12 \mathrm{mer}$ DC-specific binding peptides (Curiel et al., 2004). Fusion of these peptides with protective antigens from mucosal pathogens has given promising results in different infectious models. For example, genetic fusion of one of these peptides to hepatitis C virus non-structural protein, (NS)3, showed significantly improved immunogenicity as compared to a (NS)3 control fusion protein or (NS)3 protein alone (Mohamadzadeh et al., 2008). In a different study published from the same group, oral administration of a Bacillus anthracis protective antigen (PA) fused to a novel DC-binding peptide activated mucosal pAPCs, which in turn induced neutralizing anti-Bacillus Antibodies (sIgA) and pathogen-specific T cell immunity (Mohamadzadeh et al., 2009). In these studies, the novel, DC-targeting fusion proteins are delivered via probiotic bacteria, such as Lactobacillus. This innovative delivery approach has the following advantages: 1. Lactobacilli are part of the normal gut flora, 2. they are efficiently uptaken by $M$ cells and transported through the epithelium layers to the mucosal DCs and 3. They have the ability to induce antigen-specific IgA in the mucosa and mesenteric lymph nodes (Robinson et al., 1997; Wells and Mercenier, 2008).

Studies are in progress to identify and characterize the molecular nature of these new DC-specific peptide ligands. It is of importance to note that the majority of these peptides are strongly involved in the endocytic pathway, allowing faster and more efficient transport of the immunogenic material into the cells without impairing DC functions. Further identification of these peptides will undoubtedly create new vaccine platforms for targeting DCs via these novel DC-binding peptides.

\subsection{Lymphocyte Targeting-A Less Travelled Vaccine Approach}

In order for lymphocytes to drive effective adaptive immune responses they require at least two activation signals: The first signal is generated following recognition of antigens via the T-cell or B-cell receptors. The second signal is provided by the ligation of costimulatory molecules, such CD28 and CD40 on T and B lymphocytes, respectively. Hence, targeting these extracellular receptors with agonistic antibodies would significantly enhance both cellular and humoral immune responses; a strategy often employed and tested in cancer treatments. The main caveat of this approach, apart from by-passing the opportunity to stimulate the innate immune system, is that lymphocyte activation is usually non-specific, creating potential autoimmune complications. Nevertheless, a small number of studies have utilized agonistic antibodies against lymphocyte receptors as vaccine adjuvants in order to increase the immunogenicity of an antigen, or to generate protective immune responses against various infectious agents.

\subsection{CD21 (Complement Receptor 2) Targeting}

CD21 exists as a signal-transducing complex together with the B-cell membrane protein CD19 (Bradbury et al., 1992; Matsumoto et al., 1991). In the CD21/CD19 complex, CD21 functions as the ligand-binding subunit, while CD19 is responsible for transmitting the signal intracellularly.

When antigens coated with the complement factor $\mathrm{C} 3 \mathrm{~d}$ interact with $\mathrm{B}$ cells, the antigen binds the BCR while $\mathrm{C} 3 \mathrm{~d}$, the natural ligand of CD21, binds the latter receptor simultaneously. Thus, immunization with antigen-C3d fusion proteins may have a dual effect: It can facilitate the role of B cells as pAPCs by enhancing antigen uptake and presentation to $\mathrm{T}$ cells, while 
simultaneously enabling $B$ cells to carry out their antibody secretion effector functions. Indeed, using complement tagged proteins as antigens has shown great promise in infectious models. It has been established that complement activation plays an important role in the induction of humoral immune responses, which are key for protection especially against extracellular pathogens (Fearon, 1998; Nielsen et al., 2000). Dempsey et al. (1996) demonstrated that a recombinant protein containing three copies of $\mathrm{C} 3 \mathrm{~d}$ attached to the carboxy-terminal of Hen-Egg Lysozyme (HEL) elicited a primary response at a 10,000-fold lower concentration than that required by unmodified HEL. In a Bovine Viral diarrhea Model (BVD), immunization of cattle with a C3d-E2 viral envelope protein increased the immunogenicity of E2 by 1000 -fold, as well as the levels of BVD neutralizing antibodies (Wang et al., 2004).

In studies of greater clinical significance, administration of DNA vaccines expressing secreted forms of Haemagglutinin (sHA) of influenza virus, sHA of measles virus and HIV gp120 fused to C3d all elicited higher titres of pathogen-specific neutralizing antibodies compared to immunization with the unmodified proteins (Mitchell et al., 2003; Ross et al., 2000; 2001; Green et al., 2003 ; 2001). Therefore, targeting protein antigens to CD21 not only increases their immunogenicity but also provides a cost-effective approach due to the significantly lower antigen concentrations required to elicit robust and protective immune responses.

\subsection{2 OX40 (CD134) Targeting}

$\mathrm{O} \times 40$ is a member of the Tumor Necrosis Factor (TNF) receptor super family and is transiently expressed by $\mathrm{T}$ cells after ligation of their TCR (Mallett et al., 1990; Calderhead et al., 1993; Godfery et al., 1994). Ligation of OX40 by OX40L, mainly expressed on pAPCs, contributes to optimal T-cell function including survival and activation of effector $\mathrm{T}$ cells as well as generation of memory cells (Gramaglia et al., 2000; Maxwell et al., 2000; Rogers et al., 2001). Indeed, injection of OX40L-immunoglobulin fusion protein into mice that were infected with Cryptococcus neoformans increased the number of interferon- $\gamma$ (IFN- $\gamma$ )-secreting CD4+T cells while it decreased the $C$. neoformans burden in the lungs (Humpherys et al., 2003). In a similar study, injection of mice with an agonistic antiOX40 antibody prior to intranasal challenge with vaccinia virus increased the frequency of memory $\mathrm{CD} 8+\mathrm{T}$ cells in the lungs that were shown to mediate anti-viral properties protecting mice against lethal challenge with the virus (Salek-Ardakani et al., 2011). Hence, it is quite plausible that production of fusion proteins consisting of protective antigens and anti-OX40 antibodies may be a promising approach for targeted vaccines against various mucosal pathogens.

\section{CONCLUSION}

Prevention and cure of diseases caused by mucosal pathogens remain a challenge for science and research. Undoubtedly, the generation of protective, robust and costeffective mucosal vaccines would revolutionize medicine.

In this review, we summarized the various mucosal vaccine approaches that target extra-cellular receptors with the intention to improve transport of antigens through the mucosal epithelia, mainly by targeting $M$ cells, or to enhance long-term, protective immune responses against mucosal pathogens by specifically targeting DCs or lymphocytes (Table 1). Indeed, a wide range of cellular receptors have been exploited as candidates for targeted vaccines with variable success. The main drawbacks of most studies include the generalized over-stimulation of the immune system which could prove damaging to the host as well as the potential toxicity of some ligands. Alleviating these issues by using clinically safe molecules that can target and generate specific, robust and controlled immune responses is critical in creating successful mucosal vaccination regiments.

Understanding the mechanism of luminal antigen uptake that will deliver the antigen to the immune inductive sites is of high importance, as introduction of an antigen to the mucosal system does not guarantee the generation of an effective immune response. In addition, mucosal immunization, mainly in humans, results in compartmentalized immune responses that often lack in reproducibility. For instance, targeting DC populations in the lung parenchyma may limit the efficiency of a vaccine, owing to a relative excess of inhibitory macrophages. By contrast, delivering antigens to airway mucosal DCs, the most frequent and efficient pAPCs in the larger airways, may enhance immune responses against a pathogen. Thus, the need for a method that will analyze and assess human mucosal immune responses to vaccines remains unmet.

Furthermore, the majority of the vaccine studies utilize the specificity of antibodies to target cellular receptors. Despite this being a straight-forward approach, it is a very expensive strategy for the clinical setting. Results have indeed been promising, but vast production of these mAbs for immunization purposes would not be cost-effective, especially for Third World countries. 
Table 1. Summary of extra-cellular receptors expressed on M cells, DCs and lymphocytes that can be targeted in order to enhance transport and immunogenicity of mucosal vaccines

\begin{tabular}{llll}
\hline Cell type & Receptor & \multicolumn{1}{c}{ Ligand } & Associated Response \\
\hline M Cells & Lectin & Germagglutinin (WGA) & Enhanced antigen endocytosis \\
& Lectin & Concanavalin A (ConA) & and transport through epithelia \\
& Pattern Recognition & Lipopolysaccaride (LPS) & \\
& Ganglioside & Cholera toxin (CT) & \\
& Ganglioside & Heat-labile enterotoxin (LT) & \\
& Claudin-4 & Clostridium Perfringens enterotoxin (CPE) & \\
& Integrins & Fibronectin & \\
Integrins & Invasin & \\
Complement (C5a) & Outer membrane protein H (OmpH) & Activation of innate and adaptive \\
& Neonatal Fc (FcRn) & Fc of IgG subclasses & immune response characterized by \\
& C-type lectin (CLR) & Mannan & humoral response \\
& C-type lectin (CLR) & Mannose & \\
& Toll-like receptor (TLR) & Bacterial flagellin & \\
& Toll-like receptor (TLR) & CpG & \\
& Toll-like receptor (TLR) & Lipopolysaccharide (LPS) & \\
& Toll-like receptor (TLR) & Viral extracellular domain (M2) & \\
& Fc receptors (FcR) & Antibody Fc domain & Enhanced B-cell antigen \\
& Ganglioside & AB5 enterotoxins & presentation and antibody \\
production (CD21) & Enhanced T-cell activation and \\
& Complement & Complement factor (C3d) & memory cell formation (OX40) \\
\hline
\end{tabular}

Hence, alternative strategies for production of vaccine fusion proteins should be employed, such as utilization of recombinant DNA technology.

Finally, we have to keep in mind that the majority of these vaccine studies are done on animal models and often cannot be extrapolated to human due to the very significant differences in anatomy, physiology and immunogenicity among the different species. However, multi-disciplinary efforts and collaborations between basic scientists and clinical vaccinologists may bridge these biological gaps and enhance our understanding of the human mucosal immune system.

\section{REFERENCES}

Adamova, E., M.C. Walsh, D.R. Gosselin, K. Hale and M.T. Preissler et al., 2005. Enhanced antigenspecific antibody and cytokine responses when targeting antigen to human fcgamma receptor type $\mathrm{i}$ using an anti-human fcgamma receptor type istreptavidin fusion protein in an adjuvant-free system. Immunol. Investigat., 34: 417-429. DOI: 10.1080/08820130500265372

Agnes, M.C., A. Tan, R. Jordens, A. Geluk and B.O. Roep et al., 1998. Strongly increased efficiency of altered peptide ligands by mannosylation. Int. Immunol., 10: 1299-1304. PMID: 9786429
Applequist, S.E., E. Rollman, M.D. Wareing, M. Liden and B. Rozell et al., 2005. Activation of innate immunity, inflammation and potentiation of DNA vaccination through mammalian expression of the TLR5 agonist flagellin. J. Immunol., 175: 38823891. PMID: 16148134

Azizi, A., A. Kumar, F. Diaz-Mitoma and J. Mestecky, 2010. Enhancing oral vaccine potency by targeting intestinal M cells. PLoS Pathol., 6: 101-147. DOI: 10.1371/journal.ppat.1001147

Bachmann, M., K. Horn, A. Poleganov and J. Paulukat, 2006. Interleukin-18 secretion and Th1-like cytokine responses in human peripheral blood mononuclear cells under the influence of the toll-like receptor-5 ligand flagellin. Cell Microbiol., 8: 289-300. PMID: 16441439

Bates, J.T., A.N. Honko, A.H. Graft, N. Knock and S.B. Mizel, 2008. Mucosal adjuvant activity of flagellin in aged mice. Mechanisms Ageing Dev., 129: 271281. DOI: 10.1016/j.mad.2008.01.009

Bates, J.T., S. Uematsu, S. Akira and S.B. Mizel, 2009. Direct stimulation of tlr5+/+ CD11c + cells is necessary for the adjuvant activity of flagellin. J. Immunol., 182: 7539-7547. DOI: 10.4049/jimmunol.0804225 
Bergquist, C., T. Lagergard and J. Holmgren, 1998. Antibody responses in serum and lung to intranasal immunization with haemophilus influenzae type $b$ polysaccharide conjugated to cholera toxin B subunit and tetanus toxoid. APMIS, 106: 800-806. PMID: 9744766

Bitsaktsis, C., B.V. Iglesias, Y. Li, J. Colino and Clifford M. Snapper et al., 2012. Mucosal immunization with an unadjuvanted vaccine that targets Streptococcus pneumoniae PspA to human Fc $\gamma$ receptor type I protects against pneumococcal infection through complement- and Lactoferrin-mediated bactericidal activity. Infect. Immun., 80: 1166-1178. DOI: 10.1128/IAI.05511-11

Bitsaktsis, C., D.B. Rawool, Y. Li, N. Kurkure and B. Iglesias et al., 2009. Differential requirements for protection against mucosal challenge with Francisella tularensis in the presence versus absence of cholera toxin B and inactivated $F$. tularensis. J. Immunol., 182: 4899-4909. DOI: $10.4049 /$ jimmunol.0803242

Blank, F., P. Stumbler and C.V. Garnier, 2011. Opportunities and challenges of the pulmonary route for vaccination. Exp. Opin. Drug Delivery, 8: 547568. DOI: $10.1517 / 17425247.2011 .565326$

Bonifaz, L., D. Bonnyay, K. Mahnke, M. Rivera and R.M. Steinman et al., 2002. Efficient targeting of protein antigen to the dendritic cell receptor DEC205 in the steady state leads to antigen presentation on major histocompatibility complex class I products and peripheral $\mathrm{CD} 8+\mathrm{T}$ Cell tolerance. $\mathrm{J}$. Experim. Med., 196: 1627-1638. DOI: 10.1084/jem.20021598

Boyer, J.D., T.M. Robinson, P.C. Maciag, X. Peng and G. Pavlakis et al., 2005. DNA prime Listeria boost induces a cellular immune response to SIV antigens in the rhesus macaque model that is capable of limited suppression of SIV239 viral replication. Virology, 333: 88-101. DOI: 10.1016/j.virol.2004.12.026

Bradbury, L.E., S. Kansas, S. Levy, R.L. Evans and T.F. Tedder, 1992. The CD19/CD21 signal transducing complex of human B lymphocytes includes the target of antiproliferative antibody-1 and Leu-13 molecules. J. Immunol., 149: 2841-2850. PMID: 1383329

Brady, L.J., M.L.V. Tilburg, C.E Alford, C.E. Alford and W.P. McArthur, 2000. Monoclonal AntibodyMediated Modulation of the Humoral Immune Response against Mucosally AppliedStreptococcus mutans. Infect. Immun., 68: 1798-1805. DOI: 10.1128/IAI.68.4.1796-1805.2000
Brewer, J., M. Conacher, C.A. Hunter, M. Mohrs and F. Brombacher et al., 1999. Aluminium hydroxide adjuvant initiates strong antigen-specific Th2 responses in the absence of IL-4- or IL-13-mediated signaling. J. Immunol., 163: 6448-6454. PMID: 10586035

Brown, G.D., J. Herre, D.L. Williams, J.A. Willment and S. Gordon et al., 2003. Dectin-1 Mediates the Biological Effects of $\beta$-Glucans. J. Exp. Med., 197: 1119-1124. DOI: 10.1084/jem.20021890

Calderhead, D.M., J.E. Buhlmann, A.J. Van Den Eertwegh, E. Claassen and R.J. Noelle et al., 1993. Cloning of mouse Ox40: A T cell activation marker that may mediate T-B cell interactions. J. Immunol., 151: 5261-5271.

Chadwick, S., C. Kriegel and M. Amiji, 2009. Delivery strategies to enhance mucosal vaccination. Expert Opinion Biol., 9: 427-440. DOI: 10.1517/14712590902849224

Cheesman, C., R.B. Freedman and L.W. Ruddock, 2004. The disassembly and reassembly of mutants of Escherichia coli heat-labile enterotoxin: Replacement of proline 93 does not abolish the reassembly-competent and reassembly-incompetent states. Biochemistry, 43: 1618-1625. DOI: 10.1021/bi035499z

Chen, H., V. Torchilin and R. Langer, 1996. Lectinbearing polymerized liposomes as potential oral vaccine carriers. Pharmaceutical Res., 13: 13781383. DOI: $10.1023 / \mathrm{A}: 1016030202104$

Chiavolini, D., S. Weir, J.R. Murphy and L.M. Wetzler, 2008. Neisseria meningitidis PorB, a Toll-Like Receptor 2 Ligand, Improves the Capacity of Francisella tularensis lipopolysaccharide to protect mice against experimental tularemia. Clin. Vaccine Immunol., 15: 1322-1329. PMID: 18614668

Chionh, Y.T. and P. Sutton, 2010. Targeting of whole killed bacteria to gastrointestinal M-cells induces humoral immunity in the female reproductive tract. Gut Microbes, 1: 42-44. DOI: 10.4161/gmic.1.1.10096

Chopra, D., 1998. Creating Affluence: The A-to-Z Steps to a Richer Life. 1st Edn., New World Library, Novato, Calif., ISBN-10: 1878424343, pp: 120.

Clark, M.A., B.H. Hirst and M.A. Jepson, 2000. Lectinmediated mucosal delivery of drugs and microparticles. Drug Delivery, 43: 207-223. DOI: 10.1016/S0169-409X(00)00070-3

Cooper, E. L. E. Kauschke and A. Cossarizza, 2002. Digging for innate immunity since darwin and metchnikoff. BioEssays, 24: 319-333. DOI: 10.1002/bies. 10077 
Cuadros, C., F.J. Lopez-Hernandez, A.L. Dominguez, M. McClelland and J. Lustgarten, 2004. Flagellin fusion proteins as adjuvants or vaccines induce specific immune responses. Infect. Immun., 72: 2810-2816. DOI: 10.1128/IAI.72.5.2810-2816.2004

Curiel, T.J., C. Morris and M. Brumlik, 2004. Peptides identified through phage display direct immunogenic antigen to dendritic cells. J. Immunol., 172: 7425-7431.

Daeron, M., 1997. Fc receptor biology. Annual Rev. Immunol., 15: 203-234. DOI: 10.1146/annurev.immunol.15.1.203

Dakappagari, N., T. Maruyama, M. Renshaw, P. Tacken and R. Torensma et al., 2006. Internalizing antibodies to the C-type lectins, L-SIGN and DCSIGN, inhibit viral glycoprotein binding and deliver antigen to human dendritic cells for the induction of T cell responses. J. Immunol., 176: 426-440. PMID: 16365436

Dasari, V., C. Smith, J. Zhong, G. Scott and W. Rawlinson et al., 2011. Recombinant glycoprotein B vaccine formulation with toll-like receptor 9 agonist and immune-stimulating complex induces specific immunity against multiple strains of cytomegalovirus. J. General Virol., 92: 1021-1031. DOI: 10.1099/vir.0.029413-0

Delaney, K., J. Phipps, J. Johnson and S. Mizel, 2010. A recombinant flagellin-poxvirus fusion protein vaccine elicits complement-dependent protection against respiratory challenge with vaccinia virus in mice. Viral Immunol., 23: 201-210. DOI: 10.1089/vim.2009.0107

Dempsey, P.W., M.E. Allison, S. Akkaraju, C.C. Goodnow and D.T. Fearon, 1996. C3d of complement as a molecular adjuvant: Bridging innate and acquired immunity. Science, 271: 348350. DOI: $10.1126 /$ science. 271.5247 .348

Devriendt, B., B.G. Geest and E. Cox, 2001. Designing oral vaccines targeting intestinal dendritic cells. Expert Opin. Drug Delivery, 8: 467-483. DOI: 10.1517/17425247.2011.561312

Dhodapkar K.M., J. Krasovsky, B. Williamson and M. Dhodapkar, 2002. Antitumor monoclonal antibodies enhance cross-presentation of cellular antigens and the generation of myeloma-specific killer T cells by dendritic cells. J. Exp. Med., 195: 125-133. DOI: 10.1084/jem.20011097

Didierlaurent, A., I. Ferrero and L.A. Otten, 2004. Flagellin promotes myeloid differentiation factor 88 dependent development of Th2-type response. J. Immunol., 172: 6922-6930. PMID: 15153511
Ekong, E., D.N. Okenu, J.M. Pramanik, Q. He and G. Ananaba et al., 2009. A Vibrio cholerae ghost-based subunit vaccine induces cross-protective chlamydial immunity that is enhanced by CTA2B, the nontoxic derivative of cholera toxin. FEMS Immunol. Med. Microbiol., 55: 280-291. DOI: 10.1111/j.1574695X.2008.00493.X

Fahlen-Yrlid, L., T. Gustafsson, J. Westlund, A. Holmberg and A. Strömbeck et al., 2009. CD11chigh Dendritic cells are essential for activation of CD4+ $\mathrm{T}$ cells and generation of specific antibodies following mucosal immunization. J. Immunol., 183: 5032-5041. DOI: 10.4049/jimmunol.0803992

Fearon, D.T., 1998. The complement system and adaptive immunity. Seminars Immunol., 10: 355361. DOI: $10.1006 /$ smim. 1998.0137

Garnier, C.V. and L.P. Nicod, 2009. Immunology taught by lung dendritic cells. Swiss Med. Wkly., 139: 186192. PMID: 19137454

Garnier, C.V., M.E. Wikstrom, G. Zosky, D.J. Turner and P.D. Sly et al., 2007. Allergic airways disease develops after an increase in allergen capture and processing in the airway mucosa. J. Immunol., 179: 5748-5759. PMID: 17947647

Gessner, J.E., H. Heiken and A. Tamm, 1998. The IgG Fc receptor family. Annals Hematol., 76: 231-248. DOI: $10.1007 / \mathrm{s} 002770050396$

Godfery, W.R., F.F. Fagnoni, M.A. Harara, D. Buck and E.G. Engleman, 1994. Identification of a human OX-40 ligand, a costimulator of CD4+ T cells with homology to tumor necrosis factor. J. Exp. Med., 180: 757-762. PMID: 7913952

Godinez, I., T. Haneda, M. Raffatellu, M.D. George and T.A. Paixao et al., 2008. T cells help to amplify inflammatory responses induced by salmonella enterica serotype typhimurium in the intestinal mucosa. Infect. Immun., 76: 2008-2017. DOI: 10.1128/IAI.01691-07

Gordon, S., 2002. Pattern recognition receptors: Doubling up for the innate immune response. Cell, 111: 927-930. DOI: 10.1016/S0092-8674(02)01201-1

Gosselin, E.J., C. Bitsaktsis, Y. Li and B. Iglesias, 2009. Fc receptor-targeted mucosal vaccination as a novel strategy for the generation of enhanced immunity against mucosal and non-mucosal pathogens. Arch. Immunol., 57: 311-323. DOI: 10.1007/s00005-0090040-y

Gosselin, E.J., K. Wardwell and D.R. Gosselin, 1992. Enhanced antigen presentation using human Fc gamma receptor (monocyte/macrophage)-specific immunogens. J. Immunol., 149: 3477-3481. PMID: 1431118 
Gramaglia, I., A. Jember, S. Pippig, A. Wienberg and N. Killeen et al., 2000. The OX40 costimulatory receptor determines the development of CD4 memory by regulating primary clonal expansion. $\mathrm{J}$. Immunol., 165: 3043-3050. PMID: 10975814

Grdic, D., L. Ekman, K. Schon, K. Lindgren and J. Mattsson et al., 2005. Splenic marginal zone dendritic cells mediate the cholera toxin adjuvant effect: Dependence on the ADP-ribosyltransferase activity of the holotoxin. J. Immunol., 178: 51925202. PMID: 16210624

Green, T.D., B.R. Newton, P.A. Rota, Y. Xu and H.L. Robinson et al., 2001. C3d enhancement of neutralizing antibodies to measles hemagglutinin. Vaccine, 20: 242-248. PMID: 11567770

Green, T.D., D.C. Montefiori and T.M. Ross, 2003. Enhancement of antibodies to the human immunodeficiency virus type 1 envelope by using the molecular adjuvant C3d. J. Virol., 77: 20462055. DOI: 10.1128/JVI.77.3.2046-2055.2003

Gribar, S.C., W.M. Richardson, C.P. Sodhi and D.J. Hackam, 2008. No longer an innocent bystander: Epithelial toll-like receptor signaling in the development of mucosal inflammation. Mol. Med., 14: 645-659. DOI: 10.2119/2008-00035.Gribar

Gullberg, E., A.V. Keita, S.Y. Salim, M. Andersson and K.D. Caldwell et al., 2006. Identification of cell adhesion molecules in the human follicle-associated epithelium that improve nanoparticle uptake into the peyer's patches. J. Pharmacol. Exp. Therapeut., 319: 632-639. DOI: 10.1124/jpet.106.107847

Gupta, P.N., K. Khatri, A.K. Goyal, N. Mishra and S.P. Vyas, 2007. M-cell targeted biodegradable PLGA nanoparticles for oral immunization against hepatitis B. Drug Target, 15: 701-713. DOI: 10.1080/10611860701637982

Guyre, P.M., R.F. Graziano and J. Goldstein, 1997. Increased potency of the $\mathrm{Fc}$ receptor targeted antigen. Cancer Immunol. Immunotherapy, 45: 146148. DOI: $10.1007 / \mathrm{s} 002620050418$

Hall, L.J., S. Clare, D. Pickard, S.O. Clark and D.L.F. Kelly et al., 2009. Characterization of a live Salmonella vaccine stably expressing Mycobacterium tuberculosis Ag85B-ESAT6 fusion protein. Vaccine, 27: 6894-6904. DOI: 10.1016/j.vaccine.2009.09.007

Harokopakis, E., G. Hajishengallis and S.M. Michalek, 1998. Effectiveness of liposomes possessing surface-linked recombinant B subunit of cholera toxin as an oral antigen delivery system. Infect. Immun., 66: 4299-4304. PMID: 9712781
Hayashi, F., K.D. Smith and A. Ozinsky, 2001. The innate immune response to bacterial flagellin is mediated by toll-like receptor 5. Nature, 410: 10991103. DOI: $10.1038 / 35074106$

Hu, K.F., K. Lovgren-Bengtsson and B. Morein, 2001. Immunostimulating Complexes (ISCOMs) for nasal vaccination. Adv. Drug Delivery Rev., 51: 149-159. PMID: 11516786

Humpherys, I.R., L. Edwards, G. Walzl, A. Rae and G. Dougan et al., 2003. OX40 ligation on activated T cells enhances the control of Cryptococcus neoformans and reduces pulmonary eosinophilia. J. Immunol., 170: 6125-6132. PMID: 12794142

Hussain, N. and A.T. Florence, 1998. Utilizing bacterial mechanisms of epithelial cell entry: Invasin-induced oral uptake of latex nanoparticles. Pharmacutical Res., 15: 153-156. DOI: 10.1023/A:1011981610840

Iwasaki, A., 2007. Mucosal dendritic cells. Ann. Rev. Immunol., 25: 381-418. PMID: 17378762

Jang, M.H., M.N. Kweon, K. Iwatania, M. Yamamoto and K. Teraharad et al., 2004. Intestinal villous M cells: An antigen entry site in the mucosal epithelium. National Acad. Sci., 101: 6110-6115. DOI: 10.1073/pnas.0400969101

Jarrossay, D.G., M. Napolitani, F. Sallusto and A. Lanzavecchia, 2001. Specialization and complementarity in microbial molecule recognition by human myeloid and plasmacytoid dendritic cells. Eur. J. Immunol., 31: 3388-3393. DOI: 10.1002/1521-4141(200111)31:11

Jepson, M.A., M.A. Clark and M.A. Jepson, 2004. M cell targeting by lectins: A strategy for mucosal vaccination and drug delivery. Adv. Drug Delivery Rev., 56: 511-525. DOI: 10.1016/j.addr.2003.10.018

Jiang, W., W.J. Swiggard, C. Heufler, M. Peng and A. Mirza et al., 1995. The receptor DEC-205 expressed by dendritic cells and thymic epithelial cells is involved in antigen processing. Nature, 375: 151155. DOI: $10.1038 / 375151 \mathrm{a} 0$

Johansson-Lindbom, B., M. Svensson, O. Pabst, C. Palmqvist and G. Marquez et al., 2005. Functional specialization of gut CD103+ dendritic cells in the regulation of tissue-selective T cell homing. J. Exp. Med., 202: 1063-1073. DOI: 10.1084/jem.20051100

Kalergis, A.M. and J. Ravetch, 2002. Inducing tumor immunity through the selective engagement of activating fc $\gamma$ receptors on dendritic cells. J. Exp. Med., 195: 1653-1659. DOI: 10.1084/jem.20020338 
Kandori, H., K. Hirayama, M. Takeda and K. Doi, 1996. Histochemical, lectin-biochemical and morphometrical characteristics of intestinal goblet cells of germfree and conventional mice. Exp. Anim. Sci., 45: 155-160. DOI: 10.1538/expanim.45.155

Katz, D.E., A.J. DeLorimier, M.K. Wolf, E.R. Hall and F.J. Cassels et al., 2003. Oral immunization of adult volunteers with microencapsulated Enterotoxigenic Escherichia coli (ETEC) CS6 antigen. Vaccine, 21: 341-346. DOI: 10.1016/S0264-410X(02)00613-8

Kawamura, Y.I., R. Kawashima, Y. Shirai, R. Kato and T. Hamabata et al., 2003. Cholera toxin activates dendritic cells through dependence on GM1ganglioside which is mediated by NF-kappaB translocation. Eur. J. Immunol., 33: 3205-3212. DOI: 10.1002/eji.200324135

Keler, T., P.M. Guyre and L.A. Vitale, 2000. Targeting weak antigens to $\mathrm{CD} 64$ elicits potent humoral responses in human CD64 transgenic mice. J. Immunol.,165: 6738-6742. PMID: 11120792

Keler, T., V. Ramakrishna and M.W. Fanger, 2004. Mannose receptor targeted vaccines. Expert Opin. Biol. Theory, 4: 1953-1962. DOI: 10.1517/14712598.4.12.1953

Kensil, C. R., A. X. Mo and A. Truneh. 2004. Current vaccine adjuvants: An overview of a diverse class. Frontiers in Bioscience., 9: 2972-2988. PMID: 15353330

Kim, S.H., D. Jung, Y.I. Yang, J. Kim and K.Y. Lee et al., 2011. M cells expressing the complement C5a receptor are efficient targets for mucosal vaccine delivery. Eur. J. Immunol., 41: 3219-3229. DOI: 10.1002/eji.201141592

Klinman, D.M., K.M. Barnhart and J. Conover, 1999. CpG motifs as immune adjuvants. Vaccine, 17: 1925. DOI: $10.1016 / \mathrm{S} 0264-410 \mathrm{X}(98) 00151-0$

Krug, A., A. Towarowski, S. Britsch, S. Rothenfusser and V. Hormung et al., 2001. Toll-like receptor expression reveals CpG DNA as a unique microbial stimulus for plasmacytoid dendritic cells which synergizes with CD40 ligand to induce high amounts of IL-12. Eur. J. Immunol., 31: 3026-3037. DOI: $10.1002 / 1521-4141(2001010) 31: 10$

Lamm, M.E., 1997. Interaction of antigens and antibodies at mucosal surfaces. Annual Rev. Microbiol., 51: 311-340. DOI: 10.1146/annurev.micro.51.1.311
Lavelle, E.C. and D.T. O’Hagen, 2006. Delivery systems and adjuvants for oral vaccines. Expert Opin. Drug Delivery, 3: 747-762. DOI: 10.1517/17425247.3.6.747

Lazarevic, V., A.J. Myers, C.A. Scanga and J.L. Flynn, 2003. CD40 but not CD40L, is required for the optimal priming of $\mathrm{T}$ cells and control of aerosol $\mathrm{M}$. tuberculosis infection. Immunity, 19: 823-835. DOI: 10.1016/S1074-7613(03)00324-8

Liu, C., J. Goldstein and R.F. Graziano, 1996. F(c) gammaRI-targeted fusion proteins result in efficient presentation by human monocytes of antigenic and antagonist $\mathrm{T}$ cell epitopes. J. Clin. Investigat., 166: 2001-2007. DOI: 10.1172/JCI119004

Lore, K., M.R. Betts, J.M. Brenchley, J. Kuruppu and S. Khojasteh et al., 2003. Toll-like receptor ligands modulate dendritic cells to augment cytomegalovirus- and HIV-1-specific $\mathrm{T}$ cell responses. J. Immunol., 171: 4320-4328. PMID: 14530357

Mallett, S., S. Fossum and A.N. Barclay, 1990. Characterization of the MRC OX40 antigen of activated CD4 positive T lymphocytes--a molecule related to nerve growth factor receptor. EMBO J., 9: 1063-1068. PMID: 2157591

Mann, J.F., R. Acevedo, J.D. Campo, O. Perez and V.A. Ferro, 2009. Delivery systems: A vaccine strategy for overcoming mucosal tolerance? Expert Rev. Vaccines, 8 : 103-112. DOI: 10.1586/14760584.8.1.013

Mansour, M.K., E. Latz and S.M. Levitz, 2006. Cryptococcus neoformans glycoantigens are captured by multiple lectin receptors and presented by dendritic cells. J. Immunol., 176: 3053-3061. PMID: 16493064

Matsumoto, A.K., J. Kopicky-Burd, R.H. Carter, D.A. Tuveson and T.F. Tedder et al., 1991. Intersection of the complement and immune systems: A signal transduction complex of the B lymphocytecontaining complement receptor type 2 and CD19. J. Exp. Med., 173: 55-64. PMID: 1702139

Maxwell, J.R., A. Weinberg, R. Prell and A. Vella, 2000. Danger and OX40 receptor signaling synergize to enhance memory $\mathrm{T}$ cell survival by inhibiting peripheral deletion. J. Immunol., 164: 107-112. PMID: 10605000

Mayr, U.B., C. Haller, W. Haidinger, A. Atrasheuskaya and E. Bukin et al., 2005. Bacterial ghosts as an oral vaccine: A single dose of Escherichia coli 0157:H7 bacteria ghosts protects mice against lethal challenge. Infect. Immun., 73: 4810-4817. DOI: 10.1128/IAI.73.8.4810-4817.2005 
Mazzoni, A. and D.M. Segal, 2004. Controlling the road to dendritic cell polarization. J. Leukocyte Biol., 75: 721-730. DOI: 10.1189/jlb.1003482

McCliskie, J. and R.M. Davison, 1990. New Zealand Society of Accountants, 1990 Primary Sector Winter School: The Meat Industry, Situation and Outlook. 1st Edn., The Society, Wellington, N.Z., pp: 11.

McCluskie, M.J., Y.M. Wen and Q. Di, 1998. Immunization against hepatitis B virus by mucosal administration of antigen-antibody complexes. Viral Immunol., 11: 245-252. DOI: 10.1089/vim.1998.11.245

McDonald, W.F., J.W. Huleatt and H.G. Foellmer, 2007. A west nile virus recombinant protein vaccine that coactivates innate and adaptive immunity. J. Infect. Dis., 195: 1607-1617. DOI: 10.1086/517613

Mitchell, J.A., T.D. Green, R.A. Bright and T.M. Ross, 2003. Induction of heterosubtypic immunity to influenza a virus using a DNA vaccine expressing hemagglutinin-C3d fusion proteins. Vaccine, 21: 902-914. DOI: 10.1016/S0264-410X(02)00539-X

Mitragotri, S., 2005. Immunization without needles. Nature Rev. Immunol., 5: 905-916. DOI: 10.1038/nri1728

Mizel, S.B., A.H. Graff, N. Sriranganathan, S. Ervin and C.J. Lees et al., 2009. Flagellin-F1-V Fusion protein is an effective plague vaccine in mice and two species of nonhuman primates. Clin. Vaccine Immunol., 16: 21-28. DOI: 10.1128/CVI.00333-08

Mizel, S.B., A.P. West and R.R. Hantgan, 2003. Identification of a sequence in human toll like receptor 5 required for the binding of gram negative flagellin. J. Biol. Chem., 278: 23624-23629. DOI: 10.1074/jbc.M303481200

Mohamadzadeh, M., T. Duong, S.J. Sandwick, T. Hoover and T.R. Klaenhammer, 2009. Dendritic cell targeting of Bacillus anthracis protective antigen expressed by Lactobacillus acidophilus protects mice from lethal challenge. PNAS, 106: 4331-4336. DOI: $10.1073 /$ pnas.0900029106

Mohamadzadeh, M., T. Duong, T. Hoover and T.R. Klaenhammer, 2008. Targeting mucosal dendritic cells with microbial antigens from probiotic lactic acid bacteria. Expert Rev. Vaccines, 7: 163-174. DOI: $10.1586 / 14760584.7 .2 .163$

Mora, J.R., M. Iwata, B. Eksteen, S.Y. Song and T. Junt et al., 2006. Generation of gut-homing IgA-secreting B cells by intestinal dendritic cells. Science, 314: 1157-1160. DOI: 10.1126/science. 1132742

Neal, M.D., C. Leaphart, R. Levy, J. Prince and T.R. Billiar et al., 2006. Enterocyte TLR4 mediates phagocytosis and translocation of bacteria across the intestinal barrier. J. Immunol., 176: 3070-3079.
Neutra, M.R. and P.A. Kozlowski, 2006. Mucosal vaccines: The promise and the challenge. Nature Rev. Immunol., 6: 148-158. DOI: 10.1038/nri1777

Nguyen, C.T., S.Y. Kim, M.S. Kim, S.E. Lee and J.H. Rhee, 2011. Intranasal immunization with recombinant PspA fused with a flagellin enhances cross-protective immunity against Streptococcus pneumoniae infection in mice. Vaccine, 29: 57315739. DOI: 10.1016/j.vaccine.2011.05.095

Nielsen, C.H., E.M. Fisher and R.G. Leslie, 2000. The role of complement in the acquired immune response. Immunology, 100: 4-12. DOI: 10.1038/nri1777

Owen, R.L, 1977. Sequential uptake of horseradish peroxidase by lymphoid follicle epithelium of Peyer's patches in the normal unobstructed mouse intestine: An ultrastructural study. Gastroenterology, 72: 440-451. PMID: 832793

Pyz, E., A.S. Marshal, S. Gordon and G.D. Brown, 2006. C-type lectin-like receptors on myeloid cells. Annauls Med., 38: 242-251. DOI: 10.1080/07853890600608985

Rafiq, K., A. Bergtold and R. Clynes, 2002. Immune complex-mediated antigen presentation induces tumor immunity. J. Clin. Invest., 110: 71-79. DOI: $10.1172 / J C I 0215640$

Rask, C., M. Fredriksson, M. Linblad, C. Czerkinsky and J. Holmgren, 2000. Mucosal and systemic antibody responses after peroral or intranasal immunization: Effects of conjugation to enterotoxin B subunits and/or co-administration of free toxin as adjuvant. APMIS, 108: 178-186. DOI: 10.1034/j.16000463.2000.d01-42.x

Rawool, D.B., C. Bitsaktsis, Y. Li, D.R. Gosselin and Y. Lin et al., 2008. Utilization of Fc receptors as a mucosal vaccine strategy against an intracellular bacterium, Francisella tularensis. J. Immunol., 180: 5548-5557. PMID: 18390739

Reise-Sousa, C., 2004. Toll-like receptors and dendritic cells: for whom the bug tolls. Seminars Immunol., 16: 27-34. DOI: 10.1016/j.smim.2003.10.004

Rescigno, M. and A.D. Sabatino, 2009. Dendritic cells in intestinal homeostasis and disease. J. Clin. Invest., 119: 2441-2450. DOI: 10.1172/JCI39134

Rhodin, N.R., M.L. Van Tilburg and M.W. Oli, 2004. Further characterization of immunomodulation by a monoclonal antibody against Streptococcus mutants antigen P1. Infect. Immun., 72: 13-21. DOI: 10.1128/IAI.72.1.13-21.2004 
Robinson, K., L.M. Chamberlain, K.M. Schofield, J.M. Wells and R.W.L. Page, 1997. Mucosal and cellular immune responses elicited by recombinant Lactococcus lactis strains expressing tetanus toxin fragment. National Biotechnol., 15: 653-657. DOI: 10.1128/IAI.72.5.2753-2761.2004

Rogers, P.R., J. Song, I. Gramaglia, N. Killeen and M. Croft, 2001. $\mathrm{O} \times 40$ promotes $\mathrm{Bcl}-\mathrm{xl}$ and $\mathrm{Bcl}-2$ expression and is essential for long term survival of CD4 T cells. Immunity, 15: 445-455. DOI: 10.1016/S1074-7613(01)00191-1

Roopenian, D.C. and S. Akilesh, 2007. FcRn: the neonatal Fc receptor comes of age. National Rev. Immunol., 7: 715-725. DOI: 10.1038/nri2155

Ross, T.M., Y. Xu, R.A. Bright and H.L. Robinson, 2000. C3d enhancement of antibodies to hemagglutinin accelerates protection against influenza virus challenge. Nature Immunol., 1: 127131. DOI: $10.1038 / 77802$

Ross, T.M., Y. Xu, T.D. Green, D.C. Monteflori and H.L. Robinson, 2001. Enhanced avidity maturation of antibody to human immunodeficiency virus envelope: DNA vaccination with gp120-C3d fusion proteins. AIDS Res., 17: 829-835. DOI: $10.1089 / 088922201750252025$

Russell-Jones, G.J., 2001. The potential use of receptor mediated endocytosis for oral drug delivery. Adv. Drug Delivery Rev., 46: 59-73. DOI: 10.1016/S0169-409X (00)00127-7

Salek-Ardakani, S., M. Moutaftsi, A. Sette and M. Croft, 2011. Targeting OX40 promotes lung-resident memory CD8 $\mathrm{T}$ cell populations that protect against respiratory poxvirus infection. J. Virol., 85: 90519058. DOI: 10.1128/JVI.00619-11

Sallusto, F., M. Cella, C. Danieli and A. Lanzavecchia, 1995. Dendritic cells use macropinocytosis and the mannose receptor to concentrate macromolecules in the major histocompatibility complex class II compartment: downregulation by cytokines and bacterial products. J. Exp. Med., 182: 389-400. PMID: 7629501

Schjetne, K.W., K.M. Thompson, T. Aarvak, B. Fleckenstein and L.M. Sollid et al., 2002. A mouse C kappa-specific $\mathrm{T}$ cell clone indicates that DCSIGN is an efficient target for antibody mediated delivery of $\mathrm{T}$ cell epitopes for MHC class II presentation. Internal Med., 14: 1423-1430. DOI: 10.1093/intimm/dxf110

Schmitz, N., R. Beerli, M. Bauer, A. Jegerlehner and K. Dietmeier et al., 2012. Universal vaccine against influenza virus: Linking TLR signaling to anti-viral protection. Eur. J. Immunol., 42: 863-869. DOI: 10.1002/eji.2010441225
Singh, M., M. Vajdy, J. Gardner, M. Briones and D. O’Hagen, 2001. Mucosal immunization with HIV-1 gag DNA on cationic microparticles prolongs gene expression and enhances local and systemic immunity. Vaccine, 20: 594-602. PMID: 11672926

Snider, D.P., A. Kaubisch and D.M. Segal, 1990. Enhanced antigen immunogenicity induced by bispecific antibodies. J. Exp. Med., 171: 1957-1963. PMID: 2351931

Song, J.H., H.H. Nguyen, N. Cuburu, T. Horimoto and S.Y. Ko et al., 2008. Sublingual vaccination with influenza virus protects mice against lethal viral infection. Proc. National Acad. Sci. US Am., 105: 1644-1649. DOI: 10.1073/pnas.0708684105

Stumbles, P.A., J.W. Upham and P.G. Holt, 2003. Airway dendritic cells: Co-ordinators of immunological homeostasis and immunity in the respiratory tract. APMIS, 111: 741-755. DOI: 10.1034/j.1600-0463.2003.11107806.x

Stylianou, E., I. Pepponi, C. Dolleweerd, M. Paul and J.K. Ma, 2011. Exploring the vaccine potential of Dec-205 targeting in Mycobacterium tuberculosis infection in mice. Vaccine, 29: 2279-2286. DOI: 10.1016/j.vaccine. 2011.01 .030

Sun, K., J. Ye, D.R. Perez and D.W. Metzger, 2011. Seasonal FluMist vaccination induces cross-reactive T-cell immunity against H1N1 2009 influenza and secondary bacterial infections. J. Immunol., 186: 987-993. DOI: 10.4049/jimmunol.1002664

Tyrer, P., A.R. Foxwell, A.W. Cripps, M.A. Apicella and J.M. Kyd, 2006. Microbial pattern recognition receptors mediate M-cell uptake of a gram-negative bacterium. Infec. Immunity, 74: 625-631. DOI: 10.1128/IAI.74.1.625-631.2006

Uccini, S., M.C. Sirianni, L. Vincenzi, S. Topino and A. Stoppacciaro et al., 1997. Kaposi's sarcoma cells express the macrophage-associated antigen mannose receptor and develop in peripheral blood cultures of Kaposi's sarcoma patients. Am. J. Pathol., 150: 929938. PMID: 9060831

Uehori, J., K. Fukase, T. Akazawa, S. Uematsu and S. Akira et al., 2005. Dendritic cell maturation induced by Muramyl Dipeptide (MDP) derivatives: Monoacylated MDP confers TLR2/TLR4 activation. J. Immunol., 174: 7096-7103.

Vogel, J., 2000. Nonviral skin gene therapy. Human Gene Therapy, 11: 2253-2259. DOI: 10.1089/104303400750035780

Walsh, E., P. Moran, C. Scott, K. Mckenzie and Tom Burns et al., 2003. Prevalence of violent victimisation in severe mental illness. British $\mathrm{J}$. Psychiatry, 183: 233-238. DOI: 10.1192/03-93 
Wang, B., J.M. Kuroiwa, L.Z. He, A. Charalambous and T. Keler et al., 2009. The human cancer antigen mesothelium is more efficiently presented to the mouse immune system when targeted to the DEC205/CD205 receptor on dendritic cells. Acad. Sci., 1174: 6-17. DOI: $\quad 10.1111 /$ j.17496632.2009.04933.x

Wang, L., J.O. Sunyer and L.J. Bello, 2004. Fusion to C3d enhances the immunogenicity of the E2 glycoprotein of type 2 bovine viral diarrhea virus. J. Virol., 78: 1616-1622. DOI: 10.1128/JVI.78.4.16161622.2004

Wang, Y.F., C.G. Kelly, J.T. Karttunen, T. Whittall and P.J. Lehner et al., 2001. CD40 is a cellular receptor mediating mycobacterial heat shock protein 70 stimulation of CC-chemokines. Immunity, 15: 971983. DOI: 10.1016/S1074-7613(01)00242-4

Ward, E.S. and R.J. Ober, 2009. Multitasking by exploitation of intracellular transport functions the many faces of FcRn. Adv. Immunol., 103: 77-115. DOI: 10.1016/S0065-2776(09)03004-1

Weimer, E.T., H. Lu, N. Kock, D.J. Wozniak and S.B. Mizel, 2009. A fusion protein vaccine containing OprF epitope 8, OprI and type A and B flagellins promotes enhanced clearance of nonmucoid Pseudomonas aeruginosa. Infect. Immun., 77: 23562366. DOI: 10.1128/IAI.00054-09
Wells, J.M. and A. Mercenier, 2008. Mucosal delivery of therapeutic and prophylactic molecules using lactic acid bacteria. National Rev. Microbiol., 6: 349-362. DOI: $10.1038 /$ nrmicro 1840

Wikstrom, M.E. and P.A. Stumbles, 2007. Mouse respiratory tract dendritic cell subsets and the immunological fate of inhaled antigens. Immunol. Cell Biol., 85: 182-188. DOI: 10.1038/sj.icb.7100039

Yoshida, M., S.M. Claypool, J.S. Wagner, E. Mizoguchi and A. Mizoguchi, 2004. Human neonatal Fc receptor mediates transport of $\mathrm{IgG}$ into luminal secretions for delivery of antigens to mucosal dendritic cells. Immunity, 20: 769-783. DOI: 10.1016/j.immuni.2004.05.007

Zhang, X. A.A. Chentoufi, G. Dasgupta, A.B. Nesburn and $\mathrm{M}$. Wu et al., 2009. A genital tract peptide epitope vaccine targeting TLR-2 efficiently induces local and systemic CD8+ $\mathrm{T}$ cells and protects against herpes simplex virus type 2 challenge. Mucosal Immunol., 2: 129-139. DOI: 10:1038/mi.2008.81 